\title{
an emerging concept for general practice
}

\author{
Jan De Lepeleire, Steve Iliffe, Eva Mann and Jean Marie Degryse
}

\begin{abstract}
Ageing of the population in western societies and the rising costs of health and social care are refocusing health policy on health promotion and disability prevention among older people. However, efforts to identify at-risk groups of older people and to alter the trajectory of avoidable problems associated with ageing by early intervention or multidisciplinary case management have been largely unsuccessful. This paper argues that this failure arises from the dominance in primary care of a managerial perspective on health care for older people, and proposes instead the adoption of a clinical paradigm based on the concept of frailty. Frailty, in its simplest definition, is vulnerability to adverse outcomes. It is a dynamic concept that is different from disability and easy to overlook, but also easy to identify using heuristics (rules of thumb) and to measure using simple scales. Conceptually, frailty fits well with the biopsychosocial model of general practice, offers practitioners useful tools for patient care, and provides commissioners of health care with a clinical focus for targeting resources at an ageing population.

Keywords

disability; frail elderly; general practice.
\end{abstract}

J De Lepeleire, MD, PhD, GP, Katholieke Universiteit Leuven; J Degryse, MD, PhD, GP, Université Catholique de Louvain and Katholieke Universiteit Leuven, Belgium. S Iliffe, GP, FRCGP, GP and professor of primary care for older people, University College London, UK. E Mann, MD, GP, Institute for Health Services Research, Rankweil, Austria.

Address for correspondence

Professor Dr J De Lepeleire, Department of General Practice, KU Leuven, Kapucijnenvoer - 33 Blok J - Bus 7001, 3000 Leuven, Belgium.

E-mail: jan.delepeleire@med.kuleuven.be

Submitted: 28 May 2008; Editor's response: 12 August 2008; final acceptance: 7 January 2009.

@British Journal of General Practice

This is the full-length article of an abridged version published in print. Cite this article as: Br J Gen Pract 2009; DOI: 10.3399/bjgp09X420653.

\section{INTRODUCTION}

The western world has a rapidly ageing population which will experience a wide range of social, medical, and cultural problems as the 21st century unfolds. These problems are prompting debate about who will care for the 'oldest old' and how best to direct health and social care resources towards the older population., ${ }^{1,2}$ Ageing is associated with rising levels of dependency and comorbidity, and the older population accounts for the majority of costs in health services. Healthcare costs are increasing all over the world, prompting health services to seek reduced hospital admission and readmission rates, shorter lengths of stay, and postponement of admission to nursing homes. ${ }^{3}$ This pressure to reduce the costs of health and social services for an ageing population is causing problems for primary care, for a number of reasons.

First, primary care services are often reactive, fragmented, and poorly adapted to the management of older patients with high levels of dependency and comorbidity, leading to enthusiasm for "case management'. Second, GPs in Europe are trained in organ- and disease-based approaches and may lack knowledge about the concepts, tools, and instruments required to manage complex health problems in an ageing population. Third, the existing approaches to managing the needs of an ageing population for health services are failing to make much impact. The case for routine comprehensive screening for unmet health needs in the older population has collapsed following the Medical Research Council (MRC) trial's demonstration that there are few or no benefits to quality of life or health outcomes for older people. ${ }^{4}$ The evidence of benefit from such whole-population screening had always been thin, and the UK's '75 and over checks' had stalled long before they disappeared quietly from the GP contract in 2004. ${ }^{5}$ More targeted approaches, using senior nurses as 'community matrons' (in effect, case managers) who work intensely with older people with a history of repeated admission to hospital, or who have multiple comorbidities and polypharmacy, have also failed to show much reduction in emergency admission of older people. Policy and practice are now paralysed; although the policy objectives are clear, the means to achieve them are not. 
This current authors' opinion is that this has arisen because the increased demand for health services in an ageing population is being seen from a managerial viewpoint, rather than a clinical one. Driven by the need to contain costs, this managerial perspective works on easily measured proxies for illness and disability, such as polypharmacy or multiple comorbidities, instead of working with clinical paradigms. Targeted efforts to enhance health status and reduce service use are focused on older people with combinations of diseases (typically heart disease and diabetes), symptoms (memory loss, leg ulcers), or repeat prescription of multiple medications, forgetting that the success of medical care lies in its stabilisation of disease processes. Similarly, recurrent hospital admission is seen as a risk for future admission rather than an outcome of potentially tractable clinical conditions like gait instability, bone fragility, or multisystem failure.

The missing clinical concept is that of 'frailty'. Frailty appeared in specialist clinical discourse more than 20 years ago as one of the core issues in caring for older patients. ${ }^{6-9}$ Debates about its definition, diagnosis, status as a syndrome, independence from disability, measurement, and consequences have left us with a rich concept ideally suited to primary care. ${ }^{10-33}$ However, there has been little or no attention to the concept of frailty in the scientific literature of family medicine, so this paper will give an overview of the concept and its implications for general practice.

\section{DEFINITION OF FRAILTY}

At its simplest, frailty is a state of increased vulnerability to adverse outcomes. ${ }^{34}$ Campbell defined frailty in more complex terms, as a condition or syndrome that results from a multisystem reduction in reserve capacity, to the extent that a number of physiological systems are close to, or pass, the threshold of symptomatic clinical failure. ${ }^{11}$ In this sense, frailty can be seen as a loss of resources in several domains of functioning, which leads to a declining reserve capacity for dealing with stressors. ${ }^{18}$ Frailty is an aggregate of subthreshold decrements that affect multiple physiological systems, causing increased vulnerability. ${ }^{19}$ The shared central notion about frailty is of an older person who is at heightened risk of adverse health status change..$^{35}$ It is a multidimensional concept that considers the complex interplay of physical, psychological, social, and environmental factors. ${ }^{15}$

\section{RECOGNITION OF FRAILTY}

Fried et al argued that frailty is a distinct entity

\section{How this fits in}

Older people 'at risk' of recurrent hospital admission are currently identified using a variety of instruments that combine easily measurable proxy measures of illness, disability, and need, such as particular diagnoses (diabetes and heart disease), symptoms (memory loss and leg ulcers), or past service use

(emergency hospital admission). This approach invariably includes older people whose clinical condition is currently stable, rendering any further intervention ineffective. Not surprisingly, efforts at health promotion and disability prevention then fail to alter outcomes, at least in terms of service use. The concept of frailty avoids this failing by focusing attention on a process that, if not interrupted, invariably leads to an adverse outcome. Frailty can be recognised clinically and measured relatively easily, and therefore may be useful as a tool for improving the health of older people.

recognised by clinicians, with multiple possible manifestations and no single manifestation, by itself, being sufficient or essential in the presentation. ${ }^{12}$ They operationalised a phenotype of frailty, based on the presence of three or more core elements: weakness, tiredness, poor endurance, weight loss, low levels of physical activity, and slow gait speed. ${ }^{12}$ In this heuristic (rule of thumb), three or more of these features denote frailty, one or two denote a precursor state, and none denotes no frailty. ${ }^{36}$ These states are related to each other, and to death, in complex ways, as shown in Figure $1 .{ }^{37}$ One important aspect of this model is that both frailty and its precursor state are potentially reversible.

Both frailty as a state and the vulnerability that underpins it can easily be overlooked. GPs, like all other physicians, have been trained to focus on specific medical diseases when approaching a patient. Frailty, however, does not fit into that approach, because there is almost never a chief complaint, and the manifestations within frailty occur in combination. As frailty is a dynamic process involving change over time, longitudinal multiple assessments of the different components are often necessary. ${ }^{38}$

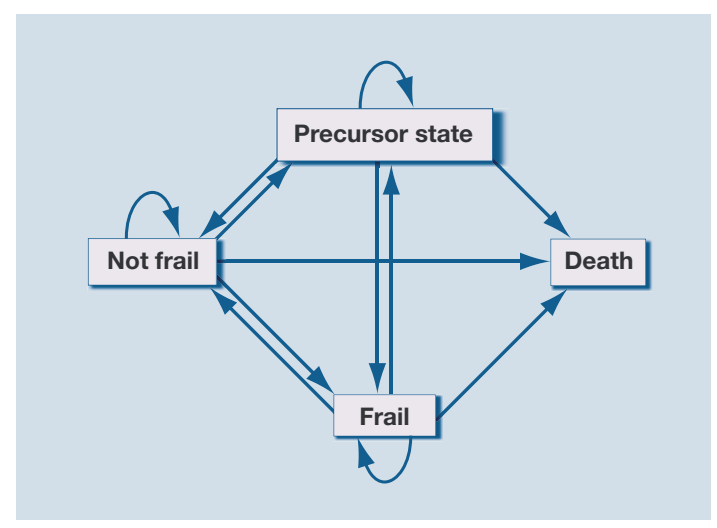

Figure 1. Relation between frailty, not frail, precursor state and death (Adapted from Gill et al, 2006). ${ }^{37}$ 


\section{FRAILTY IS DIFFERENT FROM DISABILITY}

Data from the Cardiovascular Health Study demonstrate three important features of frailty. ${ }^{36}$ First, it not only overlaps with disability and comorbidity, but also can be hidden behind them, so that professionals counting comorbidities or assessing ability may not see it. Second, onequarter of older patients show signs of frailty without either multiple comorbidities or disabilities that make them dependent on services. Frailty can appear suddenly, as an older individual who has been coping with their own resources changes into someone with multiple needs. For example, an individual who has little contact with his or her GP, few or no repeat prescriptions, and a supportive family or social network can become bedbound, confused, and highly dependent after an injurious fall. The use of the concept can therefore contribute to an anticipatory orientation in general practice, underpinning, for example, case-finding processes for dementia. ${ }^{39}$ Third, there is no linear path from comorbidity through disability to frailty, as frailty may be the cause of disability in some and the consequence in others. ${ }^{40}$

\section{FRAILTY HAS CONSEQUENCES}

The low functional reserve and unstable homeostasis of frailty have important clinical consequences, including an increased risk for multiple adverse health-related outcomes, disability, morbidity, falls, hospitalisation,

Table 1. Domains evaluated in different instruments.

\begin{tabular}{|c|c|c|c|c|}
\hline & $\begin{array}{l}\text { Groningen } \\
\text { Frailty } \\
\text { Indicator }^{19}\end{array}$ & $\begin{array}{l}\text { Frailty and Autonomy } \\
\text { Scoring Instrument of } \\
\text { Leuven (FRAIL) }^{51}\end{array}$ & $\begin{array}{l}\text { Edmonton } \\
\text { Frail } \\
\text { Scale }^{23}\end{array}$ & $\begin{array}{l}\text { Frailty } \\
\text { Staging } \\
\text { System }^{53}\end{array}$ \\
\hline ADL & - & • & • & - \\
\hline IADL & - & $\bullet$ & - & $\bullet$ \\
\hline Activities outside & • & $\bullet$ & $\bullet$ & $\bullet$ \\
\hline Sensory functions & - & - & & $\bullet$ \\
\hline Medication & - & $\bullet$ & $\bullet$ & \\
\hline Memory & - & - & $\bullet$ & \\
\hline Orientation & & $\bullet$ & - & - \\
\hline Behaviour & - & $\bullet$ & - & $\bullet$ \\
\hline Social contacts & - & - & & \\
\hline Familial functioning & - & $\bullet$ & & \\
\hline Ability to plan things & & $\bullet$ & & \\
\hline Finances & & • & & \\
\hline Feeling fit/health status & - & & $\bullet$ & \\
\hline Weight loss & - & & $\bullet$ & \\
\hline Continence & & $\bullet$ & - & - \\
\hline
\end{tabular}

$A D L=$ activities of daily living. $I A D L=$ instrumental activities of daily living. institutionalisation, and death. ${ }^{10}$ As a clinical concept, frailty has considerable value. Frailty predicts 3 year incidence or progression of disability in both mobility and activities of daily living, independent of comorbid diseases, health behaviours, and psychosocial characteristics. ${ }^{41}$ The risk for individual mortality can be predicted better by frailty than by chronological age, and mortality among older people with chronic heart failure increases with frailty. ${ }^{42,43}$ Frailty seems to be a predictor for case complexity as measured by the INTERMED instrument. ${ }^{19,44}$ An evaluation of frailty may be of great interest for those oncologists who want to identify older patients likely to develop severe toxicity and severe side-effects in response to aggressive treatment. ${ }^{45}$ Not surprisingly, frail people seem to have a significant lower quality of life. ${ }^{46}$ On the basis of US studies, it appears that frailty affects about $7 \%$ of people aged $\geq 65$ years, and about $25-40 \%$ of those aged $\geq 80$ years. ${ }^{36}$ As frailty leads to recurrent hospitalisation, institutionalisation, and death, prevention and, where possible, treatment of frailty should be high on the medical agenda. ${ }^{47}$ Because frailty appears to be a dynamic process and also potentially reversible, early recognition of frailty and early interventions should be major issues for general practice..$^{16,37,48}$

\section{FRAILTY IS MEASURABLE}

The identification of frailty with an appropriate tool should be the first step to be taken. ${ }^{49} \mathrm{~A}$ number of instruments have been developed to measure the level of frailty as part of a stepwise assessment of vulnerability. This brief, illustrative review of some instruments shows that they can be developed with different intentions, as case finder, screening instrument, or assessment tool..$^{50}$ Some of them scan the syndromal components that make up frailty, while others focus on assessment of the heightened risk. Table 1 compares the range of items present in four instruments.

The Groningen Frailty Indicator was developed as a short, simple questionnaire to be used as a case finder for older patients who would benefit from integrated care. ${ }^{19}$ For each item a score range is defined and a total score is calculated. Clinically relevant and significant differences in mean scores for physical function, emotional wellbeing, and fatigue were found between older people judged by clinicians to be frail or non-frail groups. The Frailty and Autonomy Scoring Instrument of Leuven (FRAIL) has been developed as a casefinding tool to be used without the patient being present. ${ }^{51}$ The clinician is asked to score the level of dependency concerning 12 items, grouped in a 
physical and a psychosocial cluster. The maximum score is 48 , indicating a high level of frailty. It has proved to be valid and consistent and able to be used in a stepwise procedure for the diagnosis of dementia. ${ }^{52}$

The Edmonton Frail Scale samples 10 domains. ${ }^{23}$ The maximum score is 17 and indicates a high degree of frailty. Two domains are tested using performance-based items: the 'clock' test and the 'timed get up and go' test. The other domains are mood, functional independence, medication use, social support, nutrition, health attitudes, continence, burden of medical illness, and quality of life. In a community-based sample it was a valid measure compared to the clinical impression of geriatric specialists. ${ }^{23}$

The Frailty Staging System (FSS) is a simple approach that can be used by clinicians to screen the functional status of older patients in community practice..$^{53}$ The approach relies on checking a limited number of domains that are commonly dysfunctional but often unappreciated when conventional histories and physical examinations are undertaken. The focus is on carefully selected tests of vision, hearing, upper and lower limb function, urinary incontinence, mental status, instrumental and basic activities of daily living, environmental hazards, and social support systems. Brief questions and easily observed tasks are used to obtain the information needed for a suitable, effective screening while minimising the time for administration. The score is 0 when the function is preserved and 1 when the function is lost. ${ }^{43}$

Some easy instruments are published, although discussion exists about the feasibility for general practice. ${ }^{50,54} \mathrm{GPs}$ need easy instruments that allow a two-step approach, with a simple heuristic tool (a 'rule of thumb') as the first step, and a more complex assessment as the second. ${ }^{54}$ In many European countries, GPs could integrate the first step into their daily work, and delegate the second step to a nurse, practice assistant, and sometimes secondary care. Short instruments exist and some of them have proven their clinical value in a stepwise diagnostic procedure..$^{23,51,55,56}$ Enhancement of current clinical skills by adding a more formal assessment of frailty, using either Fried et al's heuristic or a validated tool, could potentially strengthen case-finding strategies for dementia or other chronic diseases in primary care, or guide clinicians in policy choices, especially if burdensome treatment is concerned, such as chemotherapy or radiation therapy in cancer.

\section{TREATMENT OPTIONS FOR FRAILTY}

Frailty may be reversible, with opportunities for intervention at many stages in the process leading to frailty. Frailty can be understood as a continuum with intermediate states that can be modified..$^{49}$ Non-frail people can become pre-frail (precursor state) and later on frail, but this is not a unidirectional process. There is a way back from frailty to pre-fail status, and potentially to a non-frail state. ${ }^{37}$

The initial goal of treatment is an optimal management of any underlying medical illnesses that may cause frailty. The next goal is to prevent loss of muscle mass, through muscle-strengthening exercises. This loss is a consequence of normal ageing, and does not require a disease to occur, although muscle loss can be accelerated by chronic illness. It is a major cause of disability and frailty in older patients. ${ }^{57}$ The rate of muscle loss is even more pronounced in frail older persons. Numerous studies have shown that exercise is beneficial for older persons along the whole spectrum of health status, even in the frailest subset. ${ }^{58}$ Fiaterone and colleagues' trial in nursing homes with patients of median age 87 years demonstrated that a highintensity, progressive regimen of resistance exercise training improves muscle strength and size in frail older people. The changes were accompanied by improvement in mobility and an increased level of spontaneous physical activity. ${ }^{59}$ Hunter et al showed that even a low-level resistance training programme on as few as 2 days per week was associated with a lower progression of functional limitations over a 6 -month period. ${ }^{60}$ Early intervention is essential to improve physical functions or even to reverse frailty. ${ }^{61}$ Some interventions have not proven beneficial. They include increased caloric intake without an exercise programme, and hormone replacement with testosterone and dehydroepiandrosterone and growth hormones. ${ }^{62}$

\section{RELEVANCE FOR GENERAL PRACTICE?}

Frailty provides a conceptual basis for moving away from organ- and disease-based medical approaches towards a health-based integrative one, and therefore fits the biopsychosocial model of generalism very well. ${ }^{10}$ It is worthwhile in the process of integrating health and social care, for example in case-management projects. ${ }^{63}$ Frailty as a concept can have an important contribution to care at the end of life, precisely because it is not focusing on disease. ${ }^{64}$ It also can be helpful for GPs in integrating their work in nursing homes with palliative care. ${ }^{65}$ GPs already use the concept of frailty to aid clinical decision making, assess risk factors and complications, evaluate interventions, and predict outcomes, because it is a better 
measure than chronological age. ${ }^{6,23}$ For example, using clinical judgment alone, GPs are able to identify older people who would benefit from multidisciplinary interventions and those on the boundary of frailty who could benefit from exercise therapy. ${ }^{66,67}$

Enhancement of current clinical skills by adding a more formal assessment of frailty, using either Fried et al's heuristic or a validated tool, could potentially strengthen case-finding strategies in primary care. ${ }^{68}$ This may provide new opportunities for prevention, diagnosis, and care planning for older people with complex problems, and warrants investigation in experimental studies.

Research should now focus on how the transition to a more in-depth geriatric assessment in primary care can be most effectively facilitated and on the added value of such an assessment for frail, community-dwelling older people. A systematic review of the evidence on the relevance of the frailty concept (diagnostic review) or on the effectiveness of interventions based on an operational definition of the frailty concept (therapeutic review) could reveal valuable information for daily clinical work. It is important that it is known which tools work best for case finding in primary care, which for diagnosis, and which for assessing the effectiveness of interventions. Outcome measures that are meaningful for frail older people (and those who care for them) are needed, including both standardised and personalised outcomes. Work on the detection and treatment of frailty in the community will result in complex interventions, with all their attendant uncertainties and challenges. ${ }^{69}$ There is much to do.

\section{Competing interests}

The authors have stated that there are none.

Discuss this article

Contribute and read comments about this article on the Discussion Forum: http://www.rcgp.org.uk/bjgp-discuss

\section{REFERENCES}

1. Robine JM, Michel JP, Herrmann FR. Who will care for the oldest people in our ageing society? BMJ 2007; 334(7593): 570-571.

2. Tonks A. Medicine must change to serve an ageing society, eradicate age discrimination and increase resources. BMJ 2000; 319(7223): 1450-1451.

3. De Jonge P, Huyse FJ, Slaets JP, et al. Care complexity in the general hospital: results from a European study. Psychosomatics 2001; 42(3): 204-212.

4. Fletcher AE, Price GM, Ng ES, et al. Population-based multidimensional assessment of older people in UK general practice: a cluster-randomised factorial trial. Lancet 2004; 364(9446): 1667-1677.

5. Iliffe S, Gould M, Wallace P. Assessment of older people in the community: lessons from Britain's 75 and over checks. Rev Clin Gerontol 1999; 9: 305-316.

6. Rockwood K, Fox RA, Stolee P et al. Frailty in elderly people: an evolving concept. CMAJ 1994; 150(4): 489-495.

7. Fried LP. Conference on the physiologic basis of frailty. Aging Clin
Exp Res 1992; 4(3): 251.

8. Rubenstein LZ, Josephson KR, Wieland GD, et al. Effectiveness of a geriatric evaluation unit. A randomized clinical trial. $N$ Engl J Med 1984; 311(5): 1664-1670.

9. Swinne C, Cornette P, Schoevaerdts D, et al. Frailty in the medical literature. Age Ageing 1997; 26: 411-413.

10. Bergman H, Ferrucci L, Guralnik J, et al. Frailty: an emerging research and clinical paradigm - issues and controversies. J Gerontol A Biol Sci Med Sci 2007; 62(7): 731-737.

11. Campbell A. Unstable disability and the fluctuations of frailty. Age Ageing 1997; 26(4): 315-318.

12. Fried LP, Ferrucci L, Darer J, et al. Untangling the concepts of disability, frailty, and comorbidity: implications for improved targeting and care. J Gerontol A Biol Sci Med Sci 2004; 59(3): 255-263.

13. Gadow S. Frailty and strength: the dialectic in aging. Gerontologist 1983; 23(2): 144-147.

14. Hogan DB, MacKnight C, Bergman H. Models, definitions, and criteria of frailty. Aging Clin Exp Res 2003; 15(3 Suppl): 1-29.

15. Markle-Reid M, Browne G. Conceptualizations of frailty in relation to older adults. J Adv Nurs 2003; 44(1): 58-68.

16. Puts, MTE. Frailty: biological risk factors, negative consequences and quality of life. PhD Thesis/dissertation. Amsterdam: Vrije Universiteit, 2006.

17. Raphael D, Cava M, Brown I, et al. Frailty: a public health perspective. Can J Public Health 1995; 86(4): 224-227.

18. Schuurmans H, Steverink N, Lindenberg S, et al. Old or frail: what tells us more? J Gerontol A Biol Sci Med Sci 2004; 59(9): M962-M965.

19. Slaets JP. Vulnerability in the elderly: frailty. Med Clin North Am 2006; 90(4): 593-601.

20. Walston J. Frailty - the search for underlying causes. Sci Aging Knowledge Environ 2004; 2004(4): e4.

21. Woodhouse KW, Wynne H, Baillie S. Who are the frail elderly? Q J Med 1998; 68: 505-506.

22. Woodhouse KW, Campbell AJ, Schulz R. Frailty and ageing. Age Ageing 1997; 26(4): 245-246.

23. Rolfson DB, Majumdar SR, Tsuyuki RT, et al. Validity and reliability of the Edmonton Frail Scale. Age Ageing 2006; 35(5): 526-529.

24. Syddall $\mathrm{H}$, Cooper $\mathrm{C}$, Martin F, et al. Is grip strength a useful single marker of frailty? Age Ageing 2003; 32(6): 650-656.

25. Weiner DK, Duncan PW, Chandler J, et al. Functional reach: a marker of physical frailty. J Am Geriatr Soc 1992; 40(3): 203-207.

26. Banerjee S, Shamash K, McDonald A. Randomised controlled trial effect of intervention by psychogeriatric team on depression in frail elderly people at home. BMJ 1996; 313(7064): 1058-1061.

27. Brodsky J, Habib J, Hirschfeld M, et al. Care of the frail elderly in developed and developing countries: the experience and the challenges. Aging Clin Exp Res 2002; 14(4): 279-286.

28. Buchner DM, Wagner EH. Preventing frail health. Clin Geriatr Med 1992; 8(1): 1-17.

29. Freedman VA, Martin LG, Schoeni RF. Recent trends in disability and functioning among older adults in the United States: a systematic review. JAMA 2002; 288(24): 3137-3146.

30. Fried TR. Frailty and hospitalization of long-term stay nursing home residents. J Am Geriatr Soc 1997; 45(3): 265-269.

31. Kodner DL. The quest for integrated systems of care for frail older persons. Aging Clin Exp Res 2002; 14(4): 307-313.

32. Landi F, Gambassi G, Pola R, et al. Impact of integrated home care services on hospital use. J Am Geriatr Soc 1999; 47(12): 1430-1434

33. Rockwood K, Stolee P, McDowell I. Factors associated with institutionalization of older people in Canada: testing a multifactorial definition of frailty. J Am Geriatr Soc 1996; 44(5): $578-582$.

34. Frieswijk N, Buunk BP, Steverink N, et al. The effect of social comparison information on the life satisfaction of frail older persons. Psychol Aging 2004; 19(1): 183-190.

35. Martin F, Brighton P. Frailty: different tools for different purposes? Age Ageing 2008; 37(2): 129-131.

36. Fried LP, Tangen CM, Walston J, et al. Frailty in older adults: evidence for a phenotype. J Gerontol A Biol Sci Med Sci 2001; 56(3): M146-M156. 
37. Gill TM, Gahbauer EA, Allore HG, et al. Transitions between frailty states among community-living older persons. Arch Intern Med 2006; 166(4): 418-423.

38. Gill TM, Baker DI, Gottschalk M, et al. A program to prevent functional decline in physically frail, elderly persons who live at home. N Engl J Med 2002; 347(14): 1068-1074.

39. De Lepeleire J, Heyrman J. Diagnosis and management of dementia in primary care at an early stage: the need for a new concept and an adapted procedure. Theor Med 1999; 20(3): 215-228.

40. De Lepeleire J, Heyrman J. Is everyone with a chronic disease also chronically ill? Arch Public Health 2003; 61: 161-176.

41. Puts MT, Lips P, Deeg DJ. Static and dynamic measures of frailty predicted decline in performance-based and self-reported physical functioning. J Clin Epidemiol 2005; 58(11): 1188-1198.

42. Mitnitski AB, Mogilner AJ, MacKnight $\mathrm{C}$, et al. The mortality rate as a function of accumulated deficits in a frailty index. Mech Ageing Dev 2002; 123(11): 1457-1460.

43. Cacciatore F, Abete P, Mazzella F, et al. Frailty predicts long-term mortality in elderly subjects with chronic heart failure. Eur J Clin Invest 2005; 35(12): 723-730.

44. Huyse FJ, Stiefel FC, de Jonge P. Identifiers, or 'red flags', of complexity and need for integrated care. Med Clin North Am 2006 90: 703-712.

45. Ferrucci L, Guralnik JM, Cavazzini C, et al. The frailty syndrome: critical issue in geriatric oncology. Crit Rev Oncol Hemato 2003; 46(2): 127-137.

46. Puts MT, Shekary N, Widdershoven G, et al. What does quality of life mean to older frail and non-frail community-dwelling adults in the Netherlands? Qual Life Res 2007; 16(2): 263-277.

47. Puts M, Lips P, Ribbe MW. The effect of frailty on residential/nursing home admissions in the Netherlands independent of chronic disease and functional limitations. Eur J Ageing 2005; 2: 264-274.

48. Strandberg TE, Pitkala KH. Frailty in elderly people. Lancet 2007; 369(9570): 1328-1329.

49. Van Kan G, Rolland Y, Bergman H, et al. The IANA Task Force on frailty assessment of older people in clinical practice. J Nutr Health Aging 2008; 12: 29-37.

50. Ravaglia G, Forti P, Lucicesare A, et al. Development of an easy prognostic score for frailty outcomes in the aged. Age Ageing 2008; 37(2): 161-166.

51. De Lepeleire J, Ylieff M, Stessens J, et al. The validity of the Frail instrument in general practice. Arch Public Health 2004; 62 185-196.

52. De Lepeleire J, Heyrman J, Baro F, et al. A combination of tests for the diagnosis of dementia has a significant diagnostic value. J Clin Epidemiol 2005; 58(3): 217-225.

53. Lachs MS, Feinstein AR, Cooney LM Jr, et al. A simple procedure for general screening for functional disability in elderly patients.
Ann Intern Med 1990; 112(9): 699-706.

54. De Lepeleire J, Degryse J, Iliffe S, et al. Family physicians need easy instruments for frailty. Age Ageing 2008; 37(4): 484-485.

55. Huyse FJ, Lyons JS, Stiefel F, et al. Operationalizing the biopsychosocial model: the intermed. Psychosomatics 2001; 42(1): 5-13.

56. Saliba D, Elliott M, Rubenstein LZ, et al. The Vulnerable Elders Survey: a tool for identifying vulnerable older people in the community. J Am Geriatr Soc 2001; 49(12): 1691-1699.

57. Roubenoff R. Sarcopenia: a major modifiable cause of frailty in the elderly. J Nutr Health Aging 2000; 4(3): 140-142.

58. Province MA, Hadley EC, Hornbrook MC, et al. The effects of exercise on falls in elderly patients. A preplanned meta-analysis of the FICSIT Trials. Frailty and Injuries: Cooperative Studies of Intervention Techniques. JAMA 1995; 273(17): 1341-1347.

59. Fiatarone MA, O'Neill EF, Ryan ND, et al. Exercise training and nutritional supplementation for physical frailty in very elderly people. N Engl J Med 1994; 330(25): 1769-1775.

60. Hunter GR, McCarthy JP, Bamman MM. Effects of resistance training on older adults. Sports Med 2004; 34(5): 329-348.

61. Faber MJ, Bosscher RJ, Chin APM, et al. Effects of exercise programs on falls and mobility in frail and pre-frail older adults: a multicenter randomized controlled trial. Arch Phys Med Rehabil 2006; 87(7): 885-896.

62. Morley JE, Kim MJ, Haren MT. Frailty and hormones. Rev Endocr Metab Disord 2005; 6(2): 101-108.

63. Bernabei R, Landi F, Gambassi G. Randomised trial of impact of model of integrated care and case management for older people living in the community. BMJ 1998; 316(7141): 1348-1351.

64. Boockvar KS, Meier DE. Palliative care for frail older adults: 'there are things I can't do anymore that I wish I could.... JAMA 2006; 296(18): 2245-2253.

65. Gravelle H, Dusheiko M, Sheaff R, et al. Impact of case management (Evercare) on frail elderly patients: controlled before and after analysis of quantitative outcome data. BMJ 2007; 334(7583): 31-34.

66. Drennan V, Iliffe S, Haworth D, et al. The feasibility and acceptability of a specialist health and social care team for the promotion of health and independence in 'at risk' older adults. Health Soc Care Community 2005; 13(2): 136-144.

67. Dinan S, Lenihan P, Tenn T, et al. Is the promotion of physical activity in vulnerable older people feasible and effective in general practice? Br J Gen Pract 2006; 56(531): 791-793.

68. Slaets JP. Het belang van het 'Frailty-concept' bij case-finding in de geriatrie. [The importance of the frailty concept for case-finding in geriatric care.] [Dutch] Tijdschr Gerontol Geriatr 1998; 29: 276-278.

69. Craig P, Dieppe P, Macintyre S, et al. Developing and evaluating complex interventions: the new Medical Research Council guidance. $B M J$ 2008; 337: a1655. 